\title{
What is the impact of blood pressure on neurological symptoms and the risk of ESKD in primary and secondary thrombotic microangiopathies based on clinical presentation: a retrospective study
}

Jean-Michel Halimi ${ }^{1} 2^{*}$, Benjamin Thoreau ${ }^{1}$, Florent von Tokarski ${ }^{1}$, Adeline Bauvois ${ }^{1}$, Juliette Gueguen ${ }^{1}$, Nicolas Goin ${ }^{1}$, Christelle Barbet ${ }^{1}$, Sylvie Cloarec ${ }^{1}$, Elodie Mérieau' ${ }^{1}$, Sébastien Lachot ${ }^{3}$, Denis Garot ${ }^{4}$, Adrien Lemaignen ${ }^{5}$, Emmanuel Gyan ${ }^{6}$, Franck Perrotin ${ }^{7}$, Claire Pouplard ${ }^{8,9}$, François Maillot ${ }^{10}$, Philippe Gatault ${ }^{1,2}$, Bénédicte Sautenet ${ }^{1,11}$, Emmanuel Rusch ${ }^{12}$, Véronique Frémeaux-Bacchi ${ }^{13}$, Cécile Vigneau ${ }^{14}$, Guillaume Bayer ${ }^{1}$ and Fadi Fakhouri ${ }^{15}$

\begin{abstract}
Background: The impact of blood pressure on neurological symptoms and risk of end-stage kidney disease (ESKD) is unknown in primary and secondary thrombotic microangiopathies (TMAs).

Methods: We measured baseline systolic (SBP) and diastolic (DBP) BP in consecutive 563 patients with adjudicated primary and secondary TMAs, and assessed its association with the risk of ESKD.

Results: Normal BP, grade 1, 2 and 3 hypertension were present in 243 (43.1\%), 132 (23.4\%), 101 (17.9\%) and 88 (15.6\%), respectively.

Significant BP differences were noted in relation to the cause of TMA: highest BP values were found in patients with atypical hemolytic-uremic syndrome (aHUS), pregnancy, transplantation and auto-immune-related TMAs. Normal BP or grade 1 hypertension was found in 17/18 (94.4\%) patients with thrombotic thrombocytopenic patients (only 1/18 (5.6\%) had a SBP value $>150 \mathrm{mmHg}$ ). In contrast, BP values could not differentiate isolated "essential" malignant hypertension $(\mathrm{MH})$ from MH associated with aHUS (isolated MH ( $\mathrm{n=15)}$ : BP (median (IQR)): 220 (182-249)/132 (101-150) mmHg; $M H$ with aHUS ( $n=5)$ : BP: 223 (196-245)/131 (111-144) mmHg).

The risk of vigilance disturbances $(6.9 \%, 15.0 \%, 25.0 \%$, respectively), epileptic seizures $(1.5 \%, 4.0 \%, 12.5 \%$, respectively) and posterior reversible encephalopathy syndrome $(0.76 \%, 2.97 \%, 6.82 \%$, respectively) increased with increasing baseline BP values from grade 1 to grade 3 hypertension.
\end{abstract}

\footnotetext{
*Correspondence: halimi@med.univ-tours.fr

1 Service de Néphrologie-HTA, Dialyses, Transplantation Rénale, Hôpital

Bretonneau et hôpital Clôcheville, CHU Tours, 2 Bd Tonnellé, 37044 Tours

Cedex, France

Full list of author information is available at the end of the article
}

(C) The Author(s) 2022. Open Access This article is licensed under a Creative Commons Attribution 4.0 International License, which permits use, sharing, adaptation, distribution and reproduction in any medium or format, as long as you give appropriate credit to the original author(s) and the source, provide a link to the Creative Commons licence, and indicate if changes were made. The images or other third party material in this article are included in the article's Creative Commons licence, unless indicated otherwise in a credit line to the material. If material is not included in the article's Creative Commons licence and your intended use is not permitted by statutory regulation or exceeds the permitted use, you will need to obtain permission directly from the copyright holder. To view a copy of this licence, visit http://creativecommons.org/licenses/by/4.0/. The Creative Commons Public Domain Dedication waiver (http://creativecommons.org/publicdomain/zero/1.0/) applies to the data made available in this article, unless otherwise stated in a credit line to the data. 
ESKD occurred in 35/563 (6.2\%) patients (1.23\%, 2.27\%, 11.9\% and 19.3\% of patients with normal BP, grade 1, 2 and 3 hypertension, respectively). As compared to patients with normal BP $(<120 / 139 \mathrm{mmHg})$, grade 1, grade 2 and grade 3 hypertension were associated with a greater risk of ESKD in univariate (OR: 1.91 [0.83-4.40], 13.2 [3.56-48.9] and 34.8 [9.31-130], respectively) and multivariate (OR: 0.89 [0.30-2.69], 7.00 [1.57-31.3] and 19.7 [4.53-85.2], respectively) analyses. The association between BP and the risk of ESRD was unchanged after adjustment on eculizumab use (OR: 3.46 [1.41-8.49], 17.7 [4.44-70.0] and 70.6 [8.61-579], respectively). Patients with MH, regardless of its cause, had a greater risk of ESKD (OR: 26.4 [10.0-69.8] vs other patients).

Conclusions: Baseline BP differs in primary and secondary TMAs. High BP reduces the neurological tolerance of TMAs and is a powerful independent risk factor of ESKD, even after adjustment on TMA's cause.

Keywords: Blood pressure, hypertension, epidemiology, thrombotic microangiopathy, ESKD, neurological symptoms, posterior reversible encephalopathy syndrome

\section{Background}

Thrombotic microangiopathy (TMA) is a heterogenous group of diseases characterized by thrombocytopenia and mechanical hemolytic anemia with schistocytosis and elevated lactate dehydrogenase (LDH) [1]. They represent a diagnosis and therapeutic challenge for clinicians, and are associated with a poor renal outcome in the most severe cases $[1,2]$

Little is known regarding the relationship between blood pressure (BP) and TMAs. This issue has been overlooked as BP values are not even reported in large-scale TMA studies [3-8]. Nonetheless, some data suggest that the interactions between BP and TMA are important. Firstly, endothelial injury plays a pivotal role in both TMA and severe hypertension [1,9]. Secondly, TMA may induce hypertension, via mainly renal ischemia, and conversely severe hypertension may lead to TMA [10]. Thirdly, severe hypertension may interfere with the pathogenic mechanism of various TMA, and it has been linked to an activation of the complement alternative pathway $[11,12]$ and to a reduction in ADAMTS13 activity [13]. However to date, whether baseline BP differs according to the cause of TMA, and whether BP has a distinct impact on outcomes in TMAs are unknown. Any information regarding the epidemiological value of $\mathrm{BP}$ in TMAs could shed some light on the pathophysiology of acute hypertension and essential malignant hypertension $[12,13]$.

The aim of the present retrospective study was to assess the association between baseline BP and causes of TMA, and to evaluate the impact of between baseline BP on renal survival in a large cohort of consecutive patients with a wide range of adjudicated TMA.

\section{Methods}

\section{Selection of patients}

Patients with suspected TMA who were admitted to the Tours university hospital (France) between January $1^{\text {st }}, 2009$ and December $31^{\text {st }}, 2016$ were included. As previously described [14], patients were identified using 2 modes of detection: the presence of schistocytosis in the laboratory results and/or the presence of specific keywords in hospitalization discharge summaries (HDS). All patients' records were reviewed individually (manually) using all available data by 4 physicians $(\mathrm{AB}, \mathrm{GB}, \mathrm{FVT}$, $\mathrm{BT}$ ), including medical reports and electronic databases and diagnosis of TMA was confirmed or ruled out. TMA was suspected based on the presence of at least 3 of the following criteria: hemoglobin $<12 \mathrm{~g} / \mathrm{dL}$, increased LDH, low haptoglobin and schistocytosis $\geq 0.5 \%$ associated with thrombocytopenia (platelets count $<150 \mathrm{G} / \mathrm{L}$ ) $[1,2]$. Cases were adjudicated by three physicians familiar with the management of TMA and practicing in Competence Centers [14].

The first step of the adjudication was to rule in or rule out the diagnosis of TMA. Most causes of TMA are thrombocytopenic thrombotic purpura (TTP, due to severely reduced activity of ADAMTS13 (A Disintegrin And Metalloproteinase with ThromboSpondin-1 motifs, 13th member)), atypical hemolytic and uremic syndrome (aHUS, mostly due alternate pathway complement defects), shiga toxin associated TMA (STEC-HUS), TMA associated with pregnancy (usually due to pre-eclampsia, HELLP (hemolysis and elevated liver enzymes and low platelet count), post-partum hemorrhage (PPH)), STECunrelated infections, transplantation, malignancies, autoimmune diseases and medications. The second step was to identify the cause of TMA using a strict hierarchical process: first, presence of ADAMTS13 activity $\leq 10 \%$ for the diagnosis of TTP. In the absence of TTP, diagnosis of HUS-STEC was considered in the presence of shiga toxin-producing E. Coli using stool cultures and/or PCR. Then, pregnancy-related TMA was suspected in patients with HELLP, pre-eclampsia or severe delivery bleeding. The same hierarchical process was applied for other causes of TMAs (TMAs associated with specific drugs, transplantations, STEC-unrelated infections, cancers, auto-immune disease and severe/malignant hypertension 
(hypertensive retinopathy and usually diastolic arterial pressure $>120 \mathrm{mmHg}$ ). In patients with TMA and renal failure but none of the above-mentioned TMA causes, aHUS was suspected. Some rare patients had none of the above-mentioned diagnoses: we described their clinical and biochemical presentation ("other TMA" group).

\section{Baseline BP and renal outcome}

$\mathrm{BP}$ at baseline was collected and categorized as normotension (systolic/diastolic blood pressure (SBP/ $\mathrm{DPB})<140 / 90 \mathrm{mmHg}$ ), grade 1 hypertension (140$159 / 90-99 \mathrm{mmHg})$, grade 2 hypertension (160-179/100$109 \mathrm{mmHg})$ and grade 3 hypertension $(\geq 180 / 110$ $\mathrm{mmHg}$ ). In some patients, antihypertensive medications were started before hospital admission; BP values before the start of antihypertensive medications were recorded when available; if not, baseline BP at admission was noted. Malignant hypertension was clinically defined as a severe diastolic BP (DBP) (>120 mmHg) with neurological-associated symptoms or papilledema on funduscopic examination [15], regardless of the underlying cause of TMA (some patients had isolated essential malignant hypertension whereas others had malignant hypertension associated with other causes of TMAs) [14].

Acute kidney injury (AKI) was defined using the KDIGO criteria [16]. Only serum creatinine criteria were used to diagnose and stage AKI (urinary output criteria were omitted). Dialysis was recorded during hospitalization. Renal recovery at 90 days was noted to differentiate acute dialysis (dialysis duration $\leq 90$ days) from end-stage renal disease (ESRD) (dialysis duration $>90$ days) [16].

\section{Statistical analyses}

Quantitative data are presented as median and interquartile range (IQR). Qualitative data are described with percentages. Comparisons were made using Chi square test or Fischer test as appropriate for qualitative data and Wilcoxon test for quantitative data. Univariate and multivariate logistic regressions were performed for the identification of parameters associated with the risk of ESRD. SAS software (version 9.3) was used.

\section{Results}

\section{Baseline characteristics}

We identified 564 patients with TMA during the 20092016 period [17]. Baseline blood pressure (BP) value was available in 563/564 (99.8\%) patients who are included in the present study. Overall, median age was 37 (IQR: 27-57) and two-third of patients were females. TMA features (thrombocytopenia (92.2\%), anemia (96.5\%), low haptoglobin levels (90.4\%) and schistocytes (79.3\%)) were present in most patients (Table 1).
Median SBP/DBP were 142 (117-160)/84 (69-97) $\mathrm{mmHg}$. Normal BP, grade 1 , grade 2 and grade 3 hypertension were present in 243 (43.1\%), 132 (23.4\%), 101 $(17.9 \%)$ and $88(15.6 \%)$ patients, respectively (Table 1). Although significant differences regarding mean platelet count, LDH, haptoglobin and hemoglobin were noted across BP groups of patients, there was no clear doseeffect association between BP and hematological severity of TMA (Table 1). However, patients with the highest $\mathrm{BP}$ values presented more often with $\mathrm{AKI}$, proteinuria, seizures, headache, visual disturbances and posterior reversible encephalopathy syndrome (PRES) (Table 1).

\section{BP and causes of TMA}

Significant differences in BP categories were noted among TMA causes: highest BP values were found in patients with aHUS, pregnancy, transplantation and auto-immune-related TMAs.

In contrast, normal BP or grade 1 hypertension was found in most patients with TTP and infection-related TMAs (Table 1). When patients with TTP or aHUS were considered together, values provided interesting information regarding the cause of TMA: among patients with TTP, $0 / 18(0 \%)$ had a DBP value $>100 \mathrm{mmHg}$ and only $1 / 18$ (5.6\%) had a SBP value $>150 \mathrm{mmHg}$ (vs $10 / 15$ (66.7\%) and 10/15 (66.7\%), respectively, in patients with aHUS (both $\mathrm{p}<0.0001)$ ). Thus, these BP cut-off values were useful to suspect the diagnosis of TTP (negative predictive value for TTP: 100\%) or suspect aHUS (positive predictive value for aHUS: $78.0 \%$ ) in the absence of other obvious TMA causes.

In contrast, BP values could not differentiate malignant essential hypertension from aHUS in some patients. Among the 15 patients with aHUS, 5 had malignant hypertension whereas among the 20 patients with malignant hypertension, 5 patients had aHUS and 15 had malignant essential hypertension: their BP was similar (SBP/DBP: $220(182-249) / 132 \quad(101-150) \quad(n=15)$ vs 223 (196-245)/131 (111-144) mmHg $(\mathrm{n}=5))$. Among the 15 patients with aHUS, complement studies (including genetics) indicated that $12 / 15(80 \%)$ patients had complement abnormalities (low serum C3 levels $(n=3)$, low CD46 expression on granulocytes $(n=2)$, factor $\mathrm{H}$ variant $(\mathrm{n}=2), \mathrm{C} 3$ mutation $(\mathrm{n}=2)$. Among the 5 patients with aHUS and malignant hypertension, $2(40 \%)$ had a factor $\mathrm{H}$ mutation.

\section{Renal outcome Acute dialysis}

During hospitalization, 111/563 (19.7\%) patients needed dialysis and 55/563 (9.8\%) patients died (Fig.1). Acute dialysis was more frequent in patients with TMA related to aHUS $(66.7 \%, \mathrm{p}<0.0001$ vs other patients), 
Table 1 Baseline characteristics

\begin{tabular}{|c|c|c|c|c|c|c|c|c|}
\hline \multicolumn{9}{|l|}{ Baseline characteristics } \\
\hline & & & all patients & Normotension & Grade $1 \mathrm{HT}$ & Grade 2 HT & Grade 3 HT & $\mathrm{p}$ value \\
\hline & & & $n=563$ & $n=243$ & $n=132$ & $n=101$ & $\mathrm{n}=88$ & \\
\hline \multicolumn{9}{|l|}{ Clinical characteristics } \\
\hline Age & years & 563 & $37(27-57)$ & $47(21-61)$ & $35(29-56)$ & $34(26-49)$ & $34(27-47)$ & 0.1169 \\
\hline sex (\% women) & $\%$ & 550 & 62.6 & 46.9 & 73.5 & 74.3 & 76.1 & $<0.0001$ \\
\hline SBP & $\mathrm{mmHg}$ & 556 & $142(117-160)$ & $113(98-126)$ & $147(137-150)$ & $160(160-170)$ & $182(170-200)$ & $<0.0001$ \\
\hline DBP & $\mathrm{mmHg}$ & 556 & $84(69-97)$ & $66(58-77)$ & $90(82-93)$ & $100(90-100)$ & $110(108-120)$ & $<0.0001$ \\
\hline Neurologic symptoms & $\%$ & 561 & 43.9 & 37.9 & 40.5 & 48.0 & 60.2 & 0.002 \\
\hline Headache & $\%$ & 560 & 17.7 & 9.5 & 16.9 & 22.0 & 36.4 & $<0.0001$ \\
\hline Visual disturbances & $\%$ & 560 & 9.5 & 2.9 & 6.9 & 15.0 & 25.0 & $<0.0001$ \\
\hline Vigilance disturbances & $\%$ & 561 & 18.2 & 27.2 & 7.6 & 14.0 & 13.6 & $<0.0001$ \\
\hline Epileptic seizures & $\%$ & 561 & 5.5 & 5.8 & 1.5 & 4.0 & 12.5 & 0.0053 \\
\hline \multicolumn{9}{|l|}{ Biological characteristics } \\
\hline \multicolumn{9}{|l|}{ TMA-related biological parameters } \\
\hline Hemoglobin levels & $\mathrm{G} / \mathrm{L}$ & 563 & $83(68-102)$ & $77(63-91)$ & $90(74-108)$ & $91(72-104)$ & $91(73-106)$ & 0.3301 \\
\hline Anemia & $\%$ & 563 & 96.5 & 99.2 & 93.2 & 93.1 & 97.7 & 0.0042 \\
\hline mean platelet count & $\mathrm{G} / \mathrm{L}$ & 563 & $64(31-105)$ & $51(25-97)$ & $68(37-117)$ & $79(45-106)$ & $70(45-106)$ & 0.0002 \\
\hline mean platelet count $<150000$ & $\%$ & 563 & 92.2 & 91.7 & 92.4 & 96.0 & 88.6 & 0.2958 \\
\hline LDH & $x$ UNL & 514 & $3(2-5)$ & $3(2-5)$ & $3(2-5)$ & $2(2-5)$ & $2(2-5)$ & 0.001 \\
\hline Schistocytes & $\%$ & 430 & 79.3 & 84.5 & 69.7 & 73.9 & 83.9 & 0.0125 \\
\hline Low haptoglobin levels & $\%$ & 518 & 90.4 & 88.9 & 92.6 & 94.3 & 86.9 & 0.2656 \\
\hline Elevated free bilirubin & $\%$ & 548 & 49.1 & 63.7 & 42.6 & 30.9 & 38.4 & $<0.0001$ \\
\hline \multicolumn{9}{|l|}{ Other biochemical parameters } \\
\hline Serum creatinine & $\mu \mathrm{mol} / \mathrm{L}$ & 559 & $106(70-257)$ & $115(70-265)$ & $91(67-153)$ & $110(74-282)$ & $125(75-465)$ & 0.5985 \\
\hline Acute kidney injury & $\%$ & 559 & 57.6 & 61.6 & 47.3 & 59.0 & 60.9 & 0.0527 \\
\hline Proteinuria & $\%$ & 448 & 86.1 & 74.2 & 88.2 & 95.7 & 95.1 & $<0.0001$ \\
\hline Fibrinogen & $\mathrm{g} / \mathrm{L}$ & 481 & $3.90(2.60-5.00)$ & $3.15(2.18-4.50)$ & $3.01(2.00-4.11)$ & $4.25(3.10-5.20)$ & $4.43(3.14-5.16)$ & 0.0360 \\
\hline Posterior reversible encephalopthy syndrome & $\%$ & 11 & 2.0 & 0.41 & 0.76 & 2.97 & 6.82 & $<0.0001$ \\
\hline \multicolumn{9}{|l|}{ Causes of TMA } \\
\hline TTP & $\%$ & 18 & 3.2 & 4.53 & 4.55 & 0 & 5.56 & 0.0579 \\
\hline aHUS & $\%$ & 15 & 2.7 & 0.82 & 1.52 & 3.96 & 7.95 & 0.0034 \\
\hline STEC-HUS & $\%$ & 33 & 5.7 & 11.1 & 2.27 & 1.98 & 1.14 & $<0.0001$ \\
\hline Pregnancy & $\%$ & 197 & 8.2 & 34.93 & 53.79 & 59.41 & 52.17 & $<0.0001$ \\
\hline Drug & $\%$ & 144 & 25.5 & 29.6 & 25.0 & 19.8 & 21.6 & 0.2011 \\
\hline Infection & $\%$ & 178 & 31.7 & 44.5 & 25.2 & 16.8 & 10.5 & $<0.0001$ \\
\hline Transplantation & $\%$ & 96 & 17.0 & 19.8 & 17.4 & 12.9 & 13.6 & 0.3554 \\
\hline Auto-immune & $\%$ & 49 & 8.7 & 7.8 & 6.1 & 10.9 & 12.5 & 0.3068 \\
\hline Other TMA & $\%$ & 31 & 5.5 & 10.7 & 2.3 & 2.0 & 0 & $<0.0001$ \\
\hline
\end{tabular}

STEC-HUS (65.7\%, $\mathrm{p}<0.0001$ vs other patients), malignant hypertension $(60.0 \%, \mathrm{p}<0.0001$ vs other patients), transplantation $(27.1 \%, \mathrm{p}=0.0452$ vs other patients) and infections ( $25.5 \%, \mathrm{p}=0.0101$ vs other patients), and less frequent in patients with pregnancy-related TMA (4.1\%, $\mathrm{p}<0.0001$ vs other patients) (Fig.1). There was a J-curve relationship between BP categories and the proportion of acute dialysis $(20.6 \%, 18.3 \%, 12.9 \%$ and $11.4 \%$ for normal BP, grade 1 hypertension, grade 2 hypertension and grade 3 hypertension groups, respectively) (Fig. 2).

\section{ESRD at 3 months}

At 3 months, ESRD occurred in 35/111 (31.5\%) of patients with acute dialysis (35/563 (6.2\%) patients), more frequently in patients with TMAs related to drugs $(11.8 \%, p=0.0012$ vs other patients), transplantation $(14.6 \%, \mathrm{p}=0.0002$ vs other patients), aHUS (46.7\%, $\mathrm{p}<0.0001$ vs other patients) and malignant hypertension (55.0\%, $\mathrm{p}<0.0001$, vs other patients). ESRD was not observed in patients with TTP, and rare in patients with pregnancy-related TMAs (Fig.1). 


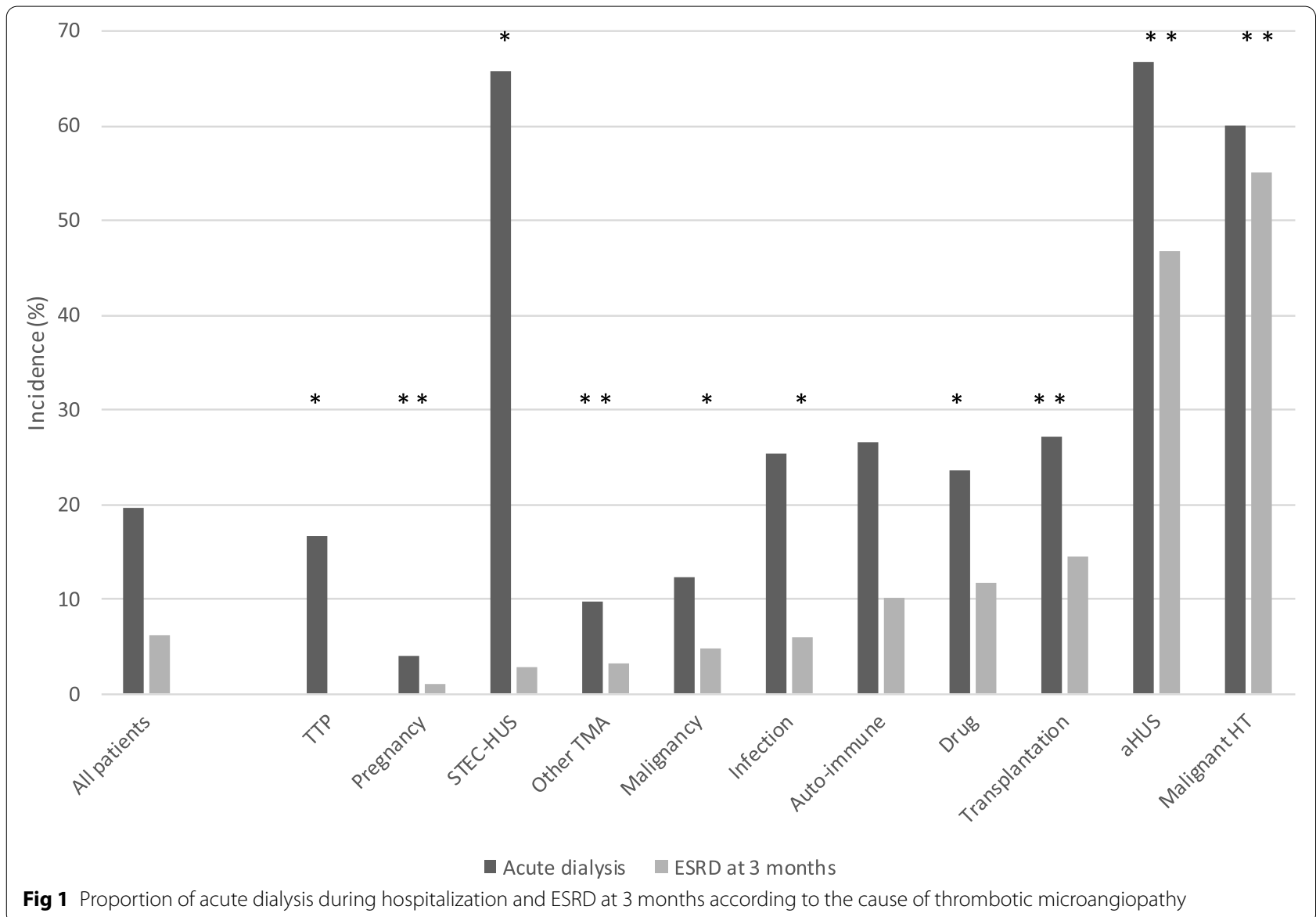

In multivariate analyses, aHUS (odds ratio (OR): 6.50 [1.71-24.7]), pregnancy (OR: 0.21 [0.05-0.94]), malignant hypertension (OR: 26.4 [10.0-69.8]) and transplantation (OR: 3.63 [1.78-7.44]) were significantly associated with ESRD in multivariate analyses (Table 2).

ESRD occurred in $1.23 \%, 2.27 \%, 11.9 \%$ and $19.3 \%$ of patients with normal BP, grade 1 , grade 2 and grade 3 hypertension groups, respectively (Fig.2a); similar doseeffect relationships between BP categories and the proportion of ESRD were found for SBP $(1.54 \%, 2.05 \%$, 13.86\%, 24.56\%, respectively, $\mathrm{p}<0.0001$ ) (Fig.2b) and DBP $(2.74 \%, 4.90 \%, 12.5 \%, 19.1 \%$, respectively, $p<0.0001)$ (Fig.2c).

In univariate analyses, BP was a powerful risk factor for ESRD: there was a dose-response relationship across BP categories and the risk of ESRD (Table 3). These results remained significant in multivariate analyses in all models used (Table 3).

Interestingly, eculizumab was used in 10/15 (66.7\%) of patients with aHUS. Of note, since 2012, only 1 patient with aHUS was not treated with eculizumab: she remained on dialysis (the diagnosis of factor $\mathrm{H}$ mutation was made several months after the disease onset).
Importantly, aHUS was no longer a risk factor for ESRD when eculizumab and BP categories were entered into the models (OR: 2.80 [0.53-14.8], $\mathrm{p}=0.2263$ ). Nevertheless, the association between BP and the risk of ESRD was unchanged after adjustment on eculizumab use (vs SBP<120 mmHg: OR (120-139 mmHg): 3.46 [1.418.49], $\mathrm{p}=0.0067) ; \mathrm{OR}(140-179 \mathrm{mmHg}): 17.7$ [4.44-70.0], p $<0.0001$; OR $(\geq 180$ mmHg: 70.6 [8.61-579], $\mathrm{p}<0.0001)$.

\section{Discussion}

We assessed the epidemiological value of BP in a large cohort of patients with various types of TMAs. Files were individually reviewed and therefore identification of included patients was not based on administrative codes but careful analysis of clinical and biological data. All consecutive TMA cases were included, thus reducing selection bias. They were adjudicated by experienced physicians.

Our first finding is that BP significantly differed across distinct causes of TMA. These differences allowed better identification of the causes of TMA. BP value at baseline was a powerful diagnostic tool: among patients with TTP, values of $\mathrm{BP}>150 \mathrm{mmHg}$ for SBP or $100 \mathrm{mmHg}$ for DBP 


\section{a.BP categories}

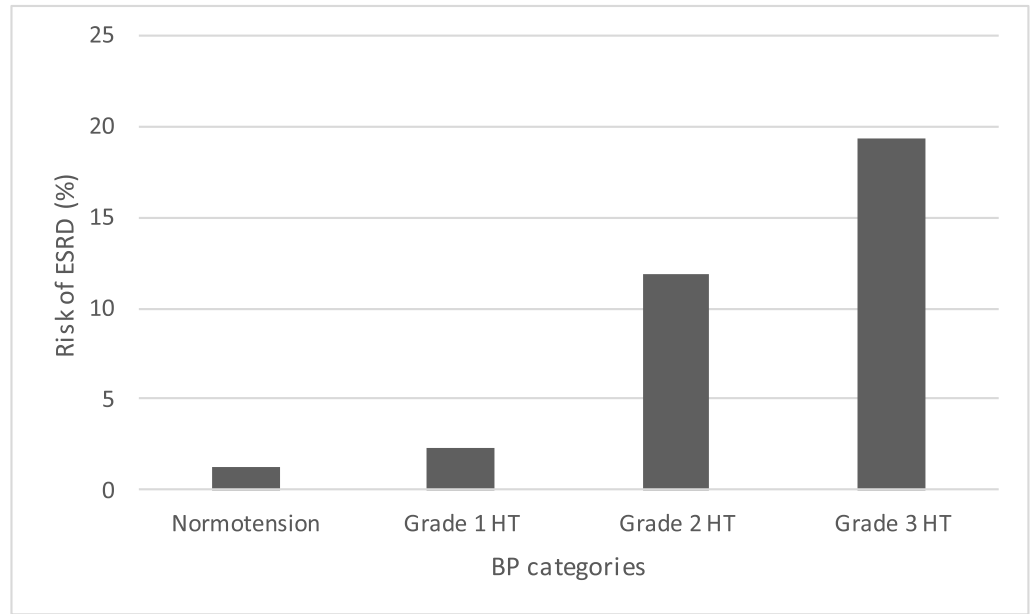

\section{b.systolic blood pressure}

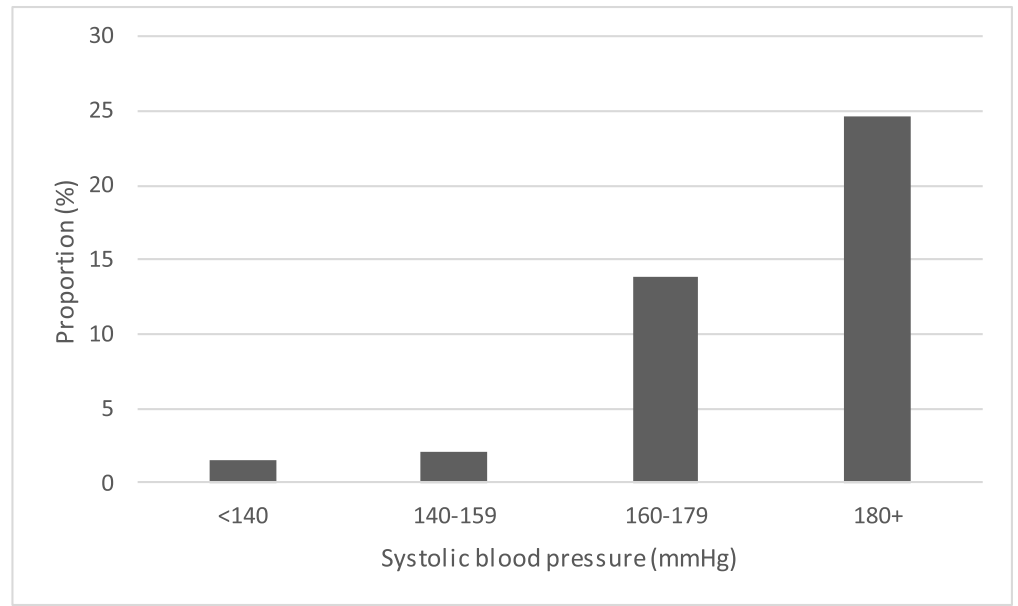

\section{c.diastolic blood pressure}

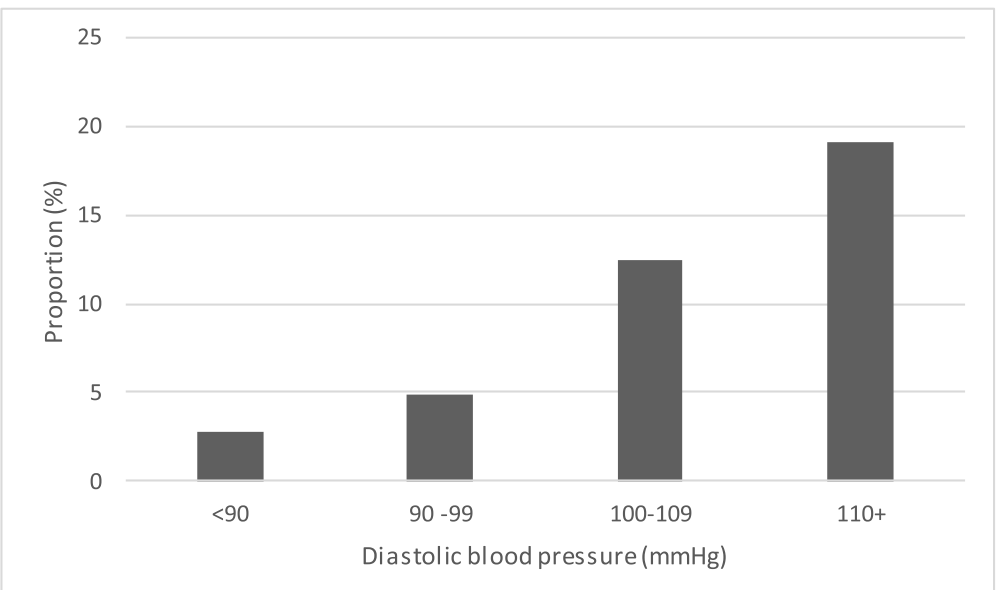

Fig. 2 Proportion of ESRD at 3 months in relation to baseline blood pressure. a.BP categories. b.systolic blood pressure. c.diastolic blood pressure 
Table 2 Risk factors for ESRD at 3 months

\begin{tabular}{|c|c|c|c|c|c|c|}
\hline \multicolumn{7}{|c|}{ Risk factors for ESRD at 3 months } \\
\hline & \multicolumn{3}{|c|}{ Univariate analysis } & \multicolumn{3}{|c|}{ Multivariate analysis } \\
\hline & OR & $95 \% \mathrm{Cl}$ & p value & OR & $95 \% \mathrm{Cl}$ & p value \\
\hline \multicolumn{7}{|l|}{ Causes of TMA } \\
\hline aHUS & 16.3 & $5.51-48.1$ & $<0.0001$ & 6.50 & $1.71-24.7$ & 0.0060 \\
\hline STEC-HUS & 0.43 & $0.06-3.22$ & 0.4103 & - & & \\
\hline Pregnancy & 0.10 & $0.03-0.44$ & 0.0020 & 0.21 & $0.05-0.94$ & 0.0413 \\
\hline Drug & 2.99 & $1.50-5.98$ & 0.0019 & - & & \\
\hline Infection & 0.94 & $0.45-1.96$ & 0.8644 & - & & \\
\hline Malignancy & 0.72 & $0.27-1.89$ & 0.4990 & - & & \\
\hline Transplantation & 3.63 & $1.78-7.44$ & 0.0004 & 2.64 & $1.15-6.05$ & 0.0216 \\
\hline Malignant hypertension & 26.4 & $10.0-69.8$ & $<0.0001$ & 16.3 & $5.51-48.1$ & $<0.0001$ \\
\hline Auto-immune disease & 1.84 & $0.68-4.97$ & 0.2312 & - & & \\
\hline Other TMA causes & 0.49 & $0.07-3.70$ & 0.4884 & - & & \\
\hline \multicolumn{7}{|l|}{ Clinical parameters } \\
\hline Age $>60$ & 1.35 & $0.61-2.97$ & 0.4551 & - & & \\
\hline Gender (female) & 2.08 & $1.04-4.17$ & 0.0365 & - & & \\
\hline De novo hypertension & 1.97 & $0.97-4.00$ & 0.0599 & - & & \\
\hline History of chronic renal disease & 3.08 & $0.35-27.2$ & 0.3104 & - & & \\
\hline \multicolumn{7}{|l|}{ Laboratory abnormalities } \\
\hline Hemoglobin levels $<10 \mathrm{G} / \mathrm{L}$ & $\mathrm{NE}$ & NE-NE & 0.9828 & - & & \\
\hline Platelet count $<150 \mathrm{G} / \mathrm{L}$ & 1.43 & $0.33-6.15$ & 0.6342 & - & & \\
\hline Presence of schistocytes & 4.04 & $0.95-17.3$ & 0.0594 & - & & \\
\hline Low haptoglobin & 1.70 & $0.40-7.34$ & 0.4752 & - & & \\
\hline Acute kidney injury & 3.37 & $1.36-8.32$ & 0.0085 & - & & \\
\hline
\end{tabular}

ESRD: end-stage renal disease; aHUS: hemolytic uremic syndrome; TMA: thrombotic microangiopathy STEC-HUS: shiga toxin E.Coli related TMA;

OR: odds ratio; $95 \% \mathrm{Cl}$ : $95 \%$ confidence interval: $\mathrm{NE}$ : not estimable

virtually excluded the diagnosis of TTP (negative predictive value for TTP: $100 \%)$. When no other obvious cause was present, these BP cut-off value allowed a strong suspicion of aHUS in most cases (positive predictive value for aHUS: 78.0\%). The identification of the cause of TMA is crucial, and any delay negatively affects patient survival $[1,18]$. Data on BP values in TMA in the literature are scarce. In 17 patients with TMA, BP values was not reported but the percentage of hypertension appeared similar in patients with secondary TMA and primary STEC-HUS, aHUS and TTP [8]. In another recent report, complement gene variants were detected in 8 patients with severe hypertension and features of TMA [12], underscoring the possibility that malignant hypertension may be a presenting feature of aHUS [12]. Our own data support this view. We believe that BP may be an additional parameter that could help clinicians rapidly distinguish aHUS from TTP in emergency settings $[19,20]$.

The second finding is that there was a striking doseresponse relationship between baseline $\mathrm{BP}$ and the risk of ESRD, regardless of the cause of TMA. Interestingly, the BP-related risk of ESRD was not restricted to patients 
Table 3 risk of ESRD at 3 months: univariate and multivariate analyses

\begin{tabular}{|c|c|c|c|c|}
\hline \multicolumn{4}{|c|}{ risk of ESRD at 3 months: univariate and multivariate analyses } & \multirow[b]{2}{*}{ Model 3} \\
\hline & Univariable & Model 1 & Model 2 & \\
\hline Normal BP & 1 & 1 & 1 & 1 \\
\hline Grade $1 \mathrm{HT}$ & $1.91(0.83-4.40)$ & $1.56(0.62-3.96)$ & $2.05(0.60-14.8)$ & $0.89(0.30-2.69)$ \\
\hline Grade $2 \mathrm{HT}$ & $13.2(3.56-48.9)$ & $12.1(3.07-47.6)$ & $8.18(1.42-47.2)$ & $7.00(1.57-31.3)$ \\
\hline Grade $3 \mathrm{HT}$ & $34.8(9.31-130)$ & $34.5(9.75-137)$ & $66.5(10.3-42.8)$ & $19.7(4.53-85.2)$ \\
\hline \multicolumn{4}{|c|}{ Model 1: age $>60$, gender, aHUS, pregnancy, transplantation-related TMA } & \\
\hline \multicolumn{2}{|c|}{ Model 2: Model $1+$ serum creatinine } & & & \\
\hline \multicolumn{3}{|c|}{ Model 3: Model $2+$ malignant hypertension } & & \\
\hline
\end{tabular}

with severe or malignant hypertension, and not even restricted to patients with hypertension as it started at a normal SBP value $(120 \mathrm{mmHg})$. Moreover, BP remained the major parameter associated with the risk of ESRD in multivariate analyses. In 62 patients with TMA, Dierkes et al found that elevated arterial pressure was a risk factor for persistent renal disease [21]. Jammes et al recently indicated that BP was a risk factor for chronic renal disease in patients with aHUS untreated by eculizumab [22]. Our results are important as they apply to various types of TMAs, regardless of their causes.

The nature of the relationship between $\mathrm{BP}$ and the pathophysiology of TMA is not clearly understood. Hypertension probably results from severe endothelial damage, a common feature to both TMAs and severe hypertension [19]. However, we did not identify a doseresponse relationship between BP levels and the severity of TMA as exemplified by the presence of schistocytes, serum level of haptoglobin, LDH, hemoglobin and platelet counts. In contrast, proteinuria and acute kidney injury were frequent in patients with the highest BP values, suggesting renal severity but not hematological severity of TMA plays a major role in BP levels. TMAs provoke acute reversible renal lesions (i.e. thrombi in arteries, thickening and obliteration of the small artery lumen, fibrinoid necrosis of arterial wall), and these lesions may heal or regress after resolution of TMAs [19]. Our results suggest that either high BP aggravates the renal lesions of TMAs or that high BP is a marker of severe and sometime irreversible renal lesions. In the absence of renal biopsy, it is difficult to analyze these findings.

Interestingly, neurological symptoms such as headaches, visual disturbances, seizures and PRES were frequently observed in patients with severe BP values, regardless of the cause of TMAs. These findings suggest that high BP plays a major role in the neurological tolerance of TMA. They also support the widespread view that BP lowering to normal levels must be achieved in hypertensive patients with TMAs to ensure a more complete recovery of TMA symptoms [23-25]. Alternatively, it is possible that thrombi in the cerebral circulation may lead to sympathetic nerve activation and subsequent increased BP, as it is observed in patients with ischemic stroke [26-28]

Interestingly, in a recent study in 20 patients with malignant hypertension, half of patients had low haptoglobin, and 12 patients had reversible encephalopathy syndrome. Among these 12 patients, 11 patients with reversible encephalopathy syndrome had both cortex and brainstem lesions. In addition, 6/7 patients with headache at presentation had reversible encephalopathy syndrome whereas $6 / 12$ without headache had also reversible encephalopathy syndrome. These lesions disappeared after BP control [29].

Autopsy studies revealed that microthrombi are present in the kidneys of most patients with TTP, typically affecting few segments of the glomeruli, but there is no significant renal infiltration of inflammatory cells in these patients unlike patients with other causes TMA and AKI in whom these lesions are more widespread and more severe $[30,31])$. These differences may explain the BP difference between TTP and with other causes of TMA such as aHUS, as less severe renal lesions may results in abnormal BP regulation by the kidneys. Moreover, baseline serum creatinine was lower in patients with TPP (1.3 $[1.0-1.7 \mathrm{mg} / \mathrm{dl}])$ than in most patients with other causes of TMA (aHUS : $(4.6$ [1.7-7.9 mg/dl] ; STEC-HUS : 4.8 [0.8-7.1 mg/dl] ; auto-immune diseases $(2.2[1.1-3.6 \mathrm{mg} /$ dl] ;transplantation $(1.9$ [1.3-3.6 mg/dl] $)$ in our study. In 
this view, high $\mathrm{BP}$ could reflect widespread parenchymal renal damage, and may not be the direct cause of AKI and subsequent ESKD. It is also important to note that patients with TTP were usually younger (38 [IQR : 31-51] than many other patients in our study (transplantationrelated TMA (51 [41-63]), auto-immune diseases (51 [3165]) which could play a lower risk of increased BP before the onset of TMA in patients with TTP.

The results of the present study are robust but they come from a single institution, and therefore they need to be replicated using a prospective study design. The results of renal biopsies could certainly shed some light on the nature of the association between baseline BP and renal survival, as it was shown that some patients with specific causes of renal diseases (such as IgA nephropathy) can present with high BP and TMA, and that the risk of ESRD was elevated in this population [32]. Kidney biopsy should probably be discussed in most patients with TMAs and initial acute kidney injury, especially in the presence of high BP $[19,31]$.

\section{Conclusion}

Our data indicate that TMAs, a group of severe hematological diseases, diversely affect the acute regulation of BP, and that BP should be carefully analyzed in patients with TMA. Epidemiological studies focused should report baseline BP values as these values provide valuable information regarding the identification of the cause of TMAs, which in turn can lead to reduction of delays in diagnosis and therapy and improved prognosis $[1,18,33]$ [34]. BP value is associated with poor neurological tolerance of TMA, and strongly suggests that strict BP control is warranted in this population. Finally, BP value,-not TMAs' hematological severity- is an excellent marker of irreversible renal damage associated with TMAs, and is a powerful independent determinant of renal survival in TMAs.

\begin{abstract}
Abbreviations
ADAMTS13: A Disintegrin And Metalloproteinase with ThromboSpondin-1 motifs, 13th member; aHUS: Atypical hemolytic and uremic syndrome; AKI: Acute kidney injury; ESRD: End-stage renal disease; HELLP: Hemolysis and elevated liver enzymes and low platelet count; IQR: Interquartile range; $\mathrm{MH}$ : Malignant hypertension; PPH: Post-partum hemorrhage; SBP/DPB: Systolic/ diastolic blood pressure; STEC-HUS: Shiga toxin associated TMA; TMA: Thrombotic microangiopathy; TTP: Thrombocytopenic thrombotic purpura.
\end{abstract}

\section{Acknowledgements \\ None}

\section{Consent to participate}

In France, this type of study does not require consent to participate (Jardé law, "Code de Santé Publique", 2016, Art. L.1122-1-3; non interventional research)".

\section{Authors' contributions}

Jean-Michel Halimi and Christelle Barbet designed the study. Guillaume

Bayer, Adeline Beauvois, Florent von Tokarski and Benjamin Thoreau collected and analyzed patients' individual files. Fadi Fakhouri, Cécile Vigneau and Jean-Michel Halimi adjudicated the TMA cases. Sébastien Lachot provided that schistocytosis database. Emmanuel Rusch was in charge of the hospital discharge summaries. All authors were involved in the clinical management of the patients. Jean-Michel Halimi drafted the manuscript and all authors reviewed and amended the manuscript.

\section{Funding}

None

\section{Availability of data and materials}

the datasets generated and/or analyzed during the current study are not publicly available due to the fact was registered as an internal research, not as public research, but are available from the corresponding author on reasonable request".

Database is available for audit.

\section{Declarations}

Ethics approval and consent to participate

Approval of the Ethics Committee of our institution was obtained ("Espace de Réflexion Ethique Région Centre" (Regional Ethic Space Center): research project n²017-013) (https://ererc.fr)

This study was conducted in accordance with the guidelines of Declaration of Helsinki.

\section{Consent for publication}

not applicable.

\section{Competing interests}

No direct interest related to this paper.

However, Fadi Fakhouri have received consultancy and/or lecture fees and/or travel support from Alexion Pharmaceuticals. Jean-Michel Halimi has received consultancy and/or lecture fees and/or travel support from Alexion Pharmaceuticals, Sanofi and Ablynx.

No competing interests for the other authors.

\section{Author details}

${ }^{1}$ Service de Néphrologie-HTA, Dialyses, Transplantation Rénale, Hôpital Bretonneau et hôpital Clôcheville, CHU Tours, 2 Bd Tonnellé, 37044 Tours Cedex, France. ${ }^{2}$ EA4245, François-Rabelais University, Tours, France. ${ }^{3}$ Service d'Hématologie Biologique, Hôpital Bretonneau, CHU Tours, Tours, France. ${ }^{4}$ Service de Médecine Intensive Réanimation, Hôpital Bretonneau, CHU Tours, Tours, France. ${ }^{5}$ Service de Maladies Infectieuses, Hôpital Bretonneau, CHU Tours, Tours, France. ${ }^{6}$ Service d'Hématologie et Thérapie Cellulaire, Hôpital Bretonneau, CHU Tours; ERL CNRS 7001, Université de Tours, Tours, France. ${ }^{7}$ Service de Gynécologie Obstétrique B, Maternité Olympe de Gouges, Hôpital Bretonneau, CHU Tours, Inserm U1253 «Imaging and Brain », François-Rabelais University, Tours, France. ${ }^{8}$ Laboratoire d'Hématologie-Hémostase, Hôpital Trousseau, CHU Tours, Tours, France. ${ }^{9}$ EA7501, François-Rabelais University, Tours, France. ${ }^{10}$ Service de Médecine interne, Hôpital Bretonneau, CHU Tours, Tours, France. ${ }^{11}$ Inserm U1246, Hôpital Bretonneau, CHU Tours, Tours, France.

${ }^{12}$ Laboratoire de Santé Publique, Hôpital Bretonneau, CHU Tours, Tours, France.

${ }^{13}$ Laboratoire d'Immunologie, Hôpital Européen Georges Pompidou, Paris, France. ${ }^{14} \mathrm{CHU}$ Pontchaillou, service de néphrologie, 35033 Rennes, Université Rennes 1, Inserm IRSET, UMR 1085, 35033 Rennes, France. ${ }^{15}$ Service of nephrology, department of medicine, CHUV and Université de Lausanne, Lausanne, Switzerland

Received: 15 April 2021 Accepted: 5 January 2022

Published online: 20 January 2022

\section{References}

1. George JN, Nester CM. Syndromes of thrombotic microangiopathy. N Engl J Med. 2014;371(7):654-66.

2. Fakhouri F, Zuber J, Fremeaux-Bacchi V, Loirat C. Haemolytic uraemic syndrome. Lancet. 2017;390(10095):681-96. 
3. George JN. The thrombotic thrombocytopenic purpura and hemolytic uremic syndromes: overview of pathogenesis (Experience of The Oklahoma TTP-HUS Registry, 1989-2007). Kidney Int Suppl. 2009;1 12:S8-S10.

4. Fremeaux-Bacchi V, Fakhouri F, Garnier A, Bienaime F, Dragon-Durey MA Ngo S, et al. Genetics and outcome of atypical hemolytic uremic syndrome: a nationwide French series comparing children and adults. Clin J Am Soc Nephrol. 2013;8(4):554-62.

5. Deford CC, Reese JA, Schwartz LH, Perdue JJ, Kremer Hovinga JA, Lammle $\mathrm{B}$, et al. Multiple major morbidities and increased mortality during long-term follow-up after recovery from thrombotic thrombocytopenic purpura. Blood. 2013;122(12):2023-9 quiz 142.

6. Scully M, Yarranton H, Liesner R, Cavenagh J, Hunt B, Benjamin S, et al. Regional UKTTP registry: correlation with laboratory ADAMTS 13 analysis and clinical features. Br J Haematol. 2008;142(5):819-26.

7. Fujimura $Y$, Matsumoto M. Registry of 919 patients with thrombotic microangiopathies across Japan: database of Nara Medical University during 1998-2008. Intern Med. 2010;49(1):7-15.

8. Kang E, Yoo SH, Oh D, Joo KW, Kim YS, Yoon SS, et al. Clinical dissection of thrombotic microangiopathy. Ann Hematol. 2017;96(10):1715-26.

9. Heathfield KW, Jewesbury EC. A Case of Malignant Hypertension with Haemolytic Anaemia: Demonstrated at the Postgraduate Medical School of London. Br Med J. 1964;2(5409):617-20.

10. Mathew RO, Nayer A, Asif A. The endothelium as the common denominator in malignant hypertension and thrombotic microangiopathy. J Am Soc Hypertens. 2016;10(4):352-9.

11. Wenzel UO, Bode M, Kohl J, Ehmke H. A pathogenic role of complement in arterial hypertension and hypertensive end organ damage. Am J Physiol Heart Circ Physiol. 2017;312(3):H349-H54.

12. Timmermans S, Abdul-Hamid MA, Vanderlocht J, Damoiseaux J, Reutelingsperger CP, van Paassen P, et al. Patients with hypertensionassociated thrombotic microangiopathy may present with complement abnormalities. Kidney Int. 2017;91 (6):1420-5.

13. van den Born BJ, van der Hoeven NV, Groot E, Lenting PJ, Meijers JC, Levi $M$, et al. Association between thrombotic microangiopathy and reduced ADAMTS13 activity in malignant hypertension. Hypertension. 2008;51(4):862-6.

14. Cremer A, Amraoui F, Lip GY, Morales E, Rubin S, Segura J, et al. From malignant hypertension to hypertension-MOD: a modern definition for an old but still dangerous emergency. J Hum Hypertens. 2016:30(8):463-6.

15. Mancia G, Fagard R, Narkiewicz K, Redon J, Zanchetti A, Bohm M, et al. 2013 ESH/ESC guidelines for the management of arterial hypertension: the Task Force for the Management of Arterial Hypertension of the European Society of Hypertension (ESH) and of the European Society of Cardiology (ESC). Eur Heart J. 2013;34(28):2159-219.

16. Kellum JA, Lameire N, Group KAGW. Diagnosis, evaluation, and management of acute kidney injury: a KDIGO summary (Part 1). Crit Care. 2013;17(1):204.

17. Bayer G, von Tokarski F, Thoreau B, Bauvois A, Barbet C, Cloarec S, et al. Etiology and Outcomes of Thrombotic Microangiopathies. Clin J Am Soc Nephrol. 2019;14(4):557-66.

18. Grall M, Azoulay E, Galicier L, Provot F, Wynckel A, Poullin P, et al. Thrombotic thrombocytopenic purpura misdiagnosed as autoimmune cytopenia: Causes of diagnostic errors and consequence on outcome. Experience of the French thrombotic microangiopathies reference centre. Am J Hematol. 2017;92(4):381-7.

19. Brocklebank V, Wood KM, Kavanagh D. Thrombotic Microangiopathy and the Kidney. Clin J Am Soc Nephrol. 2018;13(2):300-17.

20. Fakhouri F, Sadallah S, Fremeaux-Bacchi V. Malignant hypertension and thrombotic microangiopathy: complement as a usual suspect. Nephrol Dial Transplant. 2020.

21. Dierkes F, Andriopoulos N, Sucker C, Kuhr K, Hollenbeck M, Hetzel GR, et al. Indicators of acute and persistent renal damage in adult thrombotic microangiopathy. PLoS One. 2012;7(1):e30886.

22. Jamme M, Raimbourg Q, Chauveau D, Seguin A, Presne C, Perez P, et al. Predictive features of chronic kidney disease in atypical haemolytic uremic syndrome. PLoS One. 2017;12(5):e0177894.

23. van den Born BJ, Koopmans RP, van Montfrans GA. The renin-angiotensin system in malignant hypertension revisited: plasma renin activity, microangiopathic hemolysis, and renal failure in malignant hypertension. Am J Hypertens. 2007;20(8):900-6.
24. Akimoto T, Muto S, Ito C, Takahashi $\mathrm{H}$, Takeda S, Ando Y, et al. Clinical features of malignant hypertension with thrombotic microangiopathy. Clin Exp Hypertens. 2011;33(2):77-83.

25. Shantsila A, Shantsila E, Beevers DG, Lip GYH. Predictors of 5-year outcomes in malignant phase hypertension: the West Birmingham Malignant Hypertension Registry. J Hypertens. 2017;35(11):2310-4.

26. Hong YH, Lee YS, Park SH. Headache as a predictive factor of severe systolic hypertension in acute ischemic stroke. Can J Neurol Sci. 2003:30(3):210-4

27. DeLalio L, Sved AF, Stocker SD. Sympathetic Nervous System Contributions to Hypertension: Updates and Therapeutic Relevance. Can J Cardiol. 2020;36(5):712-20.

28. Walter U, Kolbaske S, Patejdl R, Steinhagen V, Abu-Mugheisib M, Grossmann A, et al. Insular stroke is associated with acute sympathetic hyperactivation and immunodepression. Eur J Neurol. 2013;20(1):153-9.

29. Mishima E, Funayama Y, Suzuki T, Mishima F, Nitta F, Toyohara T, et al. Concurrent analogous organ damage in the brain, eyes, and kidneys in malignant hypertension: reversible encephalopathy, serous retinal detachment, and proteinuria. Hypertens Res. 2021;44(1):88-97.

30. Hosler GA, Cusumano AM, Hutchins GM. Thrombotic thrombocytopenic purpura and hemolytic uremic syndrome are distinct pathologic entities. A review of 56 autopsy cases. Arch Pathol Lab Med. 2003;127(7):834-9.

31. Tsai HM. The kidney in thrombotic thrombocytopenic purpura. Minerva Med. 2007:98(6):731-47.

32. El Karoui K, Boudhabhay I, Petitprez F, Vieira-Martins P, Fakhouri F, Zuber J, et al. Impact of hypertensive emergency and complement rare variants on presentation and outcome of atypical hemolytic uremic syndrome. Haematologica. 2019

33. Gordon CE, Chitalia VC, Sloan JM, Salant DJ, Coleman DL, Quillen K, et al. Thrombotic Microangiopathy: A Multidisciplinary Team Approach. Am J Kidney Dis. 2017:70(5):715-21.

34. Mariotte E, Azoulay E, Galicier L, Rondeau E, Zouiti F, Boisseau P, et al. Epidemiology and pathophysiology of adulthood-onset thrombotic microangiopathy with severe ADAMTS13 deficiency (thrombotic thrombocytopenic purpura): a cross-sectional analysis of the French national registry for thrombotic microangiopathy. Lancet Haematol. 2016;3(5):e237-45.

\section{Publisher's Note}

Springer Nature remains neutral with regard to jurisdictional claims in published maps and institutional affiliations.

Ready to submit your research? Choose BMC and benefit from

- fast, convenient online submission

- thorough peer review by experienced researchers in your field

- rapid publication on acceptance

- support for research data, including large and complex data types

- gold Open Access which fosters wider collaboration and increased citations

- maximum visibility for your research: over $100 \mathrm{M}$ website views per year

At BMC, research is always in progress.

Learn more biomedcentral.com/submissions 